\title{
IMPERATOR DOMINUS MUNDI: A PERSPECTIVA DA AUCTORITAS NO PRINCIPADO DE OCTÁVIO AUGUSTO (27 \\ A.C- 14 D.C)
}

Rafaela de Sousa Trentini ${ }^{*}$

Resumo: O presente trabalho busca analisar a imagem elaborada a partir das virtudes como meio legitimador do Principado Romano na pessoa de Octávio Augusto. Busca-se entender como esta imagem política influencia diretamente na auctoritas, ou seja, no poder exercido e conquistado pelo princeps através do povo romano. Na historiografia sabe-se que não cabem generalizações. Contudo, a propaganda política utilizada peloprinceps buscava justificar e afirmar o seu poder tendo em vista uma nova configuração para a estrutura governativa romana, $o$ Principado, justificando desta maneira para o povo o direito a sua auctoritas na tentativa de evitar, assim, contestações ao seu poder. O objetivo desta investigação consiste em compreender como a imagem elaborada de Augusto influencia diretamente na sustentação e na elaboração de sua auctoritas. Como base para a pesquisa prioriza-se a análise das fontes primárias e secundárias do período e obras de historiadores que auxiliam na compreensão dos conceitos e da contextualização dos séculos I a.C e I d.C.

Palavras-chave: Virtus; Auctoritas; Legitimidade.

* Graduada em História na Universidade Federal do Paraná. Atualmente faz Mestrado também na Universidade Federal do Paraná, onde desenvolve pesquisas na linha de Cultura e Poder, com ênfase na Antiguidade Helenística e Principado Romano. 


\section{IMPERATOR DOMINUS MUNDI: A PERSPECTIVA DA AUCTORITAS NO PRINCIPADO DE OCTÁVIO AUGUSTO (27 A.C- 14 D.C)}

Rafaela de Sousa Trentini

O presente artigo tem como objetivo identificar e compreender como a Representação e a Propaganda Política edificada por Octávio Augusto a partir de virtudes elaboram e legitimam a sua auctoritas perante o Senado e o povo romano. Visto que a mesma era necessária para afirmar um novo tipo de governo que vinha sendo estabelecida pelo próprio Augusto, o Principado Romano.

Neste sentido, buscou-se nesta investigação analisar se a elaboração de um aparato propagandístico e de elaboração de uma imagem política segura era necessária para estabelecer e legitimar esse novo sistema governativo criado por Octávio Augusto.

Este artigo foi desenvolvido em três momentos. $\mathrm{O}$ primeiro é dedicado a uma explanação mais conceitual sobre as virtudes que permeiam o contexto aqui analisado, e como elas influenciam na vida política romana, mas, sobretudo quais as suas origens e usos. Quais as mudanças e transformações de conceitos gregos para o uso político romano. No segundo momento, buscou-se apresentar uma contextualização sobre o personagem aqui analisado, Octávio 
Augusto. E por fim, no terceiro momento, busca-se compreender como a propaganda política que Augusto faz de si mesmo influenciava diretamente na elaboração e na legitimação de sua auctoritas. ${ }^{1}$

O século I a.C foi um período muito conturbado da História Romana, permeado por intensas guerras civis e disputas pelo poder da República. Neste ínterim aparecem personagens que se destacam neste momento como Caio Mario, Sulla, Pompeu, Júlio César, Marco Antônio que buscam o poder de várias formas. Mas principalmente Octávio Augusto, que cria um novo sistema de governo, com o apoio da aristocracia senatorial e do povo romano. Neste sentido, compreender como ele elabora esse novo sistema, mas mais do que isso, como ele consegue a auctoritas necessária para governar de forma soberana em meio a uma sociedade republicana demonstra-se importante para a compreensão do Principado Romano.

Após as diversas tentativas por parte dos generais em obter o poder, baseado numa relação de poder pessoal, ou seja, baseado em uma só figura que representa toda a instituição, a República já não podia mais ser restaurada, de acordo com Norma Musco Mendes².

${ }^{1}$ Conceito latino que define a real influência e poder de uma determinada pessoa em seus subordinados, baseado em uma relação de confiança e respeito e não poder imposto com o uso da força, mas sim conquistado pelo indivíduo.

2 MENDES , Norma Musco. “Sistema Político do Principado". In: MENDES, Norma M. e SILVA, Gilvan. (orgs.) Repensando o Império Romano.Rio de Janeiro: Mauad; Vitória: EDUFES, 2006. 
Com o assassinato de César, a República entra em uma grande crise sucessória, e assim também em uma guerra civil. O Senado já não se sustentava sem um representante único, os senadores já não possuíam forças suficientes para reestabelecer seu antigo regime político.

Os conjurados que, a 15 de Março de 44 a.C assassinaram César, estavam imbuídos de um único desejo: eliminar o 'tirano' que, havia cinco anos, impedia o livre funcionamento das instituições republicanas. Eles não imaginavam que estas instituições estavam condenadas por meio século de anarquia e pelo renovar quase incessante das guerras civis. ${ }^{3}$

Deste modo cria-se o Segundo Triunvirato, onde o poder é dividido entre os três homens com maior representação política daquele momento, Marco Antônio e Lépido, ambos generais de César, e Octávio sobrinho neto e herdeiro do ditador de acordo com o seu testamento, lido por Antônio em praça pública.

Com o afastamento de Lépido, Antônio e Octávio entraram em um combate direto. Antônio alia-se a Cleópatra, rainha do Egito adotando, inclusive os costumes egípcios e desejando que quando de sua morte, seu corpo fosse enterrado em Alexandria. Por ser romano, isto caracterizou-se como um insulto aos seus compatriotas, aproveitando-se destas infelizes declarações de Antônio, que de certo modo influenciou a opinião pública contra

${ }^{3}$ GRIMAL, Pierre. O Século de Augusto. Lisboa: Edições 70, 2008, p. 21. 
este, Octávio declara-o como traidor da República e afirma que o mesmo tem a intenção de tornar Roma uma monarquia ao estilo helenístico. Deste modo afirma-se como o defensor da República, das suas tradições e de seu povo. Em 31 a.C. na Batalha do Ácio Octávio sai vencedor, derrotando Antônio e Cleópatra, e assim anexando o Egito às províncias romanas. Deste modo, Octávio é o único soberano de Roma neste momento, e é declarado como o salvador de Roma.

A versão oficial justifica essa guerra como justa, caracterizada como a defesa da liberdade e da paz contra um soberano inimigo, romano degenerado que tentava subjugar a Itália e o Ocidente sob o governo de uma Rainha Oriental. Ácio representou o choque entre as forças do herdeiro de César, do Senado, do povo e dos deuses de Roma contra uma Rainha e os deuses do Nilo, e consequentemente afastou a ameaça de orientalização tão temida pela aristocracia romana, pois significava um regime político nos moldes de uma monarquia helenística. ${ }^{4}$

Com a vitória sobre Antônio, Octávio conquista a imagem de restaurador da República e da liberdade (vindex libertatis). Deste modo, essa posição o afastava de uma ditadura e de uma imagem tirânica, a qual César havia recebido. Durante todos estes embates com Antônio, Octávio procurou produzir uma imagem segura,

\footnotetext{
${ }^{4}$ MENDES, op. cit., p. 25.
} 
inclusive como um homem escolhido por Apolo para levar a glória. ${ }^{5}$ Otávio, desta maneira consegue a legitimidade necessária para permanecer no Consulado sem objeções por parte do Senado, da Aristocracia e do povo romano e lá permanece até o ano de 27 a.C.

At the age of nineteen, on my own initiative and my own expense, I raised an army by means of wich I restored liberty to the republic, wich had been opressed by the tyranny of a faction. ${ }^{6}$

Neste mesmo ano de 27 a.C. Octávio percebe que a sua saída do poder já não era mais aceitável pelas diversas camadas romanas, bem como a sua figura tornou-se indispensável para todos, caracterizando-se mais em uma relação de dependência do seu poder, mas também pela admiração e o respeito que o mesmo possuía para com o povo romano. Sendo assim, com uma grande percepção política, Octávio convoca uma reunião extraordinária no Senado, onde o mesmo planeja devolver todos os seus poderes ao Senado e ao povo romano.

Nesta sessão Octávio abdica de todos os seus poderes e os devolve para o Senado Romano a fim de colocar em prática o que ele vinha elaborando, a imagem de defensor da República e do mos

\footnotetext{
${ }^{5}$ GRIMAL, op. cit., p.50.

${ }^{6}$ AUGUSTUS. Res Gestae Divi Augusti. London: Loeb Classical Library, 1924, p. 347. Tradução do autor: "Aos dezenove anos levantei um exército por minha própria iniciativa e custas. Eu restaurei a liberdade para a República que vinha sendo oprimida por um tirano e por uma facção".
} 
maiorum. O Senado, por sua vez, instantaneamente recusa e ainda pede para Octávio que permaneça no poder por mais tempo. O mesmo ainda tenta negar, porém o Senado insiste, afirmando que esta também era a vontade do povo romano. Ainda lhe oferece novos poderes militares e administrativos, que estavam representados através dos títulos de imperator (chefe miltar) e princeps (primeiro cidadão/ primeiro senador). É neste momento que se caracteriza o início do Principado Romano. Três dias mais tarde Octávio recebe ainda o mais importante título de sua carreira política, o de Augusto, que significava um ser sagrado, título aplicado anteriormente apenas aos deuses. Este título irá conferir ao agora chamado Gaius Octavius Julius Caesar (Caio Octávio Júlio César) uma sacralidade e uma legitimidade perante todo o povo romano e a aristocracia senatorial, proporcionando que o Principado seja efetivo e que o mesmo tornese um soberano. O principado de Augusto irá durar até 14 d.C. ano de sua morte, mas também sobreviverá por séculos. Sua obra foi duradoura e forte por muito tempo, e depois ficaria conhecida como Império Romano.

Octávio Augusto torna-se soberano de Roma, principalmente pela acumulação de diversos poderes em sua mão, quase todas as estruturas políticas estavam agregadas para si. Recebe além dos títulos de Imperator, Princeps e Augusto, a tribunicia potestas, ou seja, a iniciativa legislativa, Tribuno da Plebe, conseguindo assim o poder de vetar decisões no Senado e representar a plebe romana. E por fim 
recebe também o título de Pontifex Maximus, que lhe garantia a chefia da religião romana.

Deste modo observa-se que todas as estruturas governativas estavam concentradas em Octávio Augusto, tornando-o soberano, e de certa forma incontestável. Havia revoltas e contestações ao seu poder, no entanto eram logo eliminadas pelas forças de Augusto. Assim, fica caracterizada uma forma de modelo pessoal de governo, na qual um indivíduo é associado diretamente a todas as formas de poder de um determinado governo.

Augusto busca fixar uma imagem de supremo defensor das tradições, traditiones, também do mos maiorum, ou seja, os costumes dos antepassados, e da República Romana, tal como ela foi em seu início. Busca inclusive, fazer uma política antagônica a de seu tio avô Júlio César em diversos aspectos, a fim de conseguir a legitimidade por parte da aristocracia. Em todo momento ele afirma ser integrante e defensor da um sistema republicano, e busca afastar-se de insinuações monárquicas.

\footnotetext{
"Fui por dez anos seguidos, triúnviro da república que se organizava. Por quarenta anos, até o dia em que escrevi essas linhas, fui princeps do senado". ${ }^{7}$
}

Esta afirmação do próprio Augusto demonstra que ele não se colocava acima da República, pelos menos na retórica. Ele promete

\footnotetext{
7 AUGUSTO. Os feitos do Divino Augusto. Belo Horizonte. Editoria UFMG, 2007, p. 129.
} 
reorganizar a república, e assim afirma que a estruturava novamente, ainda coloca que sempre esteve trabalhando em conjunto com o Senado, apenas era o princeps do mesmo.

\begin{abstract}
"Promoveu mudanças e instituiu muita coisa nova nos assuntos militares, e também fez retroceder algumas características ao modo antigo. Exerceu a disciplina de forma extremamente severa". 8
\end{abstract}

Com esta política de apresentar-se como um defensor e de um guia da República a sua ordem natural, Augusto conquista a aristocracia romana. Por intermédio do princeps, as elites romanas tencionavam manter o imperium e reviver os ideais da res publica, ou seja, preservar a sua base material mediante a proteção da propriedade privada, a manutenção dos seus privilégios sociais e a garantia de segurança pessoal do indivíduo, afastando assim os abusos do tempo das guerras civis. Neste sentido a atuação de Otávio Augusto foi bastante conservadora, possibilitando a consolidação das transformações socioeconômicas do final do período republicano. ${ }^{9}$

Desta maneira, Augusto conquista a confiança da aristocracia romana, o que possibilita assim uma maior liberdade para agir perante o senado, que pertencia a este grupo social. Do mesmo modo

\footnotetext{
${ }^{8}$ SUETÔNIO. A vida do divino Augusto. Belo Horizonte. Editora UFMG, 2007, p. 66.

${ }^{9}$ MENDES, op. cit., p. 26.
} 
Augusto conquista o Senado com essa mesma propaganda, a de defensor da República, onde ele só estava ali para guiá-la para o seu tempo de auge novamente, apenas para retirá-la da crise em que vivia, principalmente com as guerras civis. Com este semblante Octávio Augusto conquista definitivamente a auctoritas perante esta aristocracia. Principalmente quando delega o seu poder ao Senado e ao povo romano.

Por fim buscou-se, compreender como ele estabelece uma propaganda de si mesmo, para afirmar o seu real poder. Primeiramente, são vistos os usos políticos das virtudes no mundo romano e como Augusto apropria-se destas virtudes, pois era uma tradição romana o homem político utilizar-se de virtudes para afirmar-se em determinados cargos.

A sociedade romana, em muitos aspectos apropriou-se da cultura grega, inclusive na utilização de virtudes para definir o indivíduo, principalmente político. Neste sentido a política romana estava permeada destes aspectos. Sendo assim, Augusto utiliza-se bastante deste mecanismo para se afirmar no poder. Octávio Augusto estava criando um novo sistema de governo, para tanto precisava de elementos que o legitimassem. Deste modo ele utiliza-se tanto das virtudes, para elaborar uma imagem segura para todos os cidadãos, como também a propaganda política, para que sua imagem fosse disseminada.

As virtudes principais de Augusto são a uirtus (valor), clementia (clemência), pietas (piedade) e iustitia (justiça), além de 
várias outras. $\mathrm{O}$ princeps utiliza-as para elaborar sua imagem, de um homem justo e clemente, que possui valor, e que é o mais preparado para restaurar a república e levar Roma a sua antiga glória. Para que esta imagem fosse distribuída, Augusto utilizou-se de elementos propagandísticos, como obras literárias, tanto de gênero histórico como de epopeia. Dois grandes exemplos desta propaganda, onde aparecem de forma intensa as suas virtudes. Na epopeia Eneida, Augusto não é citado abertamente, mas insinuado como o homem mais preparado, mas principalmente Sagrado, principalmente por ser descendente de César, que por sua vez é descendente de Rômulo (fundador de Roma), que tem descendência com Enéias (fugitivo de Tróia) e que é filho de Vênus. Ou seja, apresenta-o como um homem sagrado e preparado para governar. Da mesma forma o mesmo apresenta-se como o princeps mais virtuoso, clemente e justo, mas também sempre um defensor dos ideais republicanos. Em sua Res Gestae Divii Augusti. Esta propaganda política é o elemento que mais contribui para a legitimação de sua auctoritas, pois sem a mesma, Augusto não seria apresentado como um cidadão político de características e valores maiores que os outros, e assim daria margem para grandes contestações ao seu poder.

Para entender como Augusto elabora esse sistema, utilizou-se três tipos de fontes Históricas. A primeira, e mais importante, foi a Res Gestae Divii Augustii, documento escrito pelo próprio Augusto, e desta forma, analisado com maior cautela, em que o mesmo descreve todos os seus atos de governo, bem como exalta a sua própria figura 
com as virtudes políticas. Analisou-se também a epopeia Eneida, escrita por Virgílio, mas encomendada por Augusto, desta forma cheia de intenções, para apresentar o mito fundacional romano, bem como conectar Augusto as maiores tradições romanas, as de sua fundação, mas também ao sagrado, como a descendência com Vênus. E por fim também foi utilizada "A Vida do Divino Augusto", inserida na obra de Suetônio $A$ vida dos doze Césares, escrita pouco mais de um século após a morte de Augusto, mas foi utilizada para compreender como a imagem do mesmo será perpetuada nos anos seguintes, e como sobreviverá o Principado.

Com relação à confiabilidade destas fontes a primeira Res Gestae Divii Augustii pode-se considerar confiável, pois foi esculpida ainda em vida de Augusto em uma placa de bronze e colocada em seu túmulo na versão latina, a qual ainda permanece no local, outra versão grega foi colocada em praça pública na cidade de Antioquia. Para esse estudo foi utilizado tanto a versão retirada diretamente do latim inscrito na placa de bronze, embora ainda não tenha sido analisado, para isso utilizou-se a tradução diretamente do latim para o inglês. Quanto a Eneida e A Vida dos Doze Césares, contamos com diversas traduções feitas durante dois milênios, o que complica a análise de seu texto original. No entanto, devido às intensas cópias realizadas na Idade Média, possuem exemplares em latim na Europa, disponíveis na internet, onde é possível consultar a obra com maior confiabilidade. Para esse estudo, foram utilizadas traduções para o Português que fossem indicadas como confiáveis. 
O estudo deste objeto visa buscar elementos na formação do Principado Romano por Octávio Augusto que possibilitem compreender a ação política baseada em princípios morais, o que caracteriza a propaganda política utilizada pelo princeps para fortalecer e legitimar a sua imagem e o seu sistema de governo. Justifica-se tal escolha pela pertinência de compreender as estruturas políticas antigas, haja vista as crises políticas dos dias atuais, na possibilidade de análise dos processos de estruturação política. Entender a base do sistema de governo romano possibilita identificar determinados aspectos que, direta ou indiretamente, se relacionam às atribulações ocorridas nos sistemas de governo de alguns regimes contemporâneos.

Justifica-se tal abordagem por considerar pertinente entender como a propaganda política romana é elaborada através de elementos morais, como as virtudes, que delimitam a imagem de determinados indivíduos. E como esta propaganda influencia diretamente na elaboração, no fortalecimento, na sustentação e na auctoritas de indivíduos e regimes políticos no poder.

Priorizou-se uma análise mais detalhada das fontes históricas, de acordo com a metodologia proposta por Arnaldo Momigliano ${ }^{10}$, onde o mesmo afirma que as fontes devem ser o elemento principal em uma análise, aliada com outros autores que possibilitem análises

\footnotetext{
${ }^{10}$ MOMIGLIANO, Arnaldo. Raízes Clássicas da Historiografia Moderna. São Paulo. Edusc, 2004.
} 
sobre o assunto, mas a fonte deve ser o elemento prioritário, principalmente no que se refere à História Antiga, devido a grande distância no tempo. Portanto, adotou-se a metodologia proposta por Momigliano, priorizando a análise das fontes sem negligenciar as interpretações realizadas sobre o tema.

Manuel Gervás contribui em relação a analise do período histórico e do objeto afirmando que as virtudes elaboram e fortalecem os regimes políticos do mundo antigo, no caso o Império e o Principado Romano. Sendo assim, o autor dedica-se a análise das virtudes como elementos sustentadores da imagem de seus governantes, principal ideia utilizada na investigação. Gervás analisa intensamente as virtudes, e procura, da mesma forma, apresentar como elemento mais importante da investigação as fontes históricas, e também identificar os conceitos antigos das virtudes para que não ocorram anacronismos.

Concluímos, portanto, que a Propaganda Política era necessária para elaboração e a legitimação tanto de Octávio Augusto como também do sistema criado por ele, o Principado Romano. Pois de acordo com as tradições romanas, os homens políticos deveriam ser virtuosos, e mais do que ser, deveriam demonstrar ser. Desta forma, Augusto tomou atenção para tal prática e assim conquistou a confiança da aristocracia e do povo romano, conseguindo a auctoritas necessária para governar e manter-se no poder, ao contrário do que aconteceu com seu pai adotivo, Júlio César. Sendo assim, a propaganda política da imagem idealizada de Augusto criada 
por ele mesmo foi um elemento ímpar em relação a sua importância na elaboração de sua auctoritas e de seu sistema de governo.

\section{Bibliografia}

CORASSIN, Maria Luiza. "Comentários sobre a Res Gestae Divi Augusti”. In: JOLY. Fábio Duarte (Org.). História e Retórica: Ensaios sobre historiografia antiga. São Paulo: Alameda, 2007.

. "A Idealização do Príncipe na Ideologia Aristocrática de Roma”. Boletim do CPA, Campinas, nº 4, jul/dez, 1997.

FINLEY, Moses. História Antiga. São Paulo: Martins Fontes, 1994.

EHRHARDT, Marcos Luis. O Arquiteto Social: Sêneca e a Construção de Modelos para a Sociedade Romana nos tempos do Principado a partir da Historia Magistra Vitae. Tese de doutoramento no programa de Pós Graduação em História. Setor de Ciências Humanas, Letras e Artes da Universidade Federal do Paraná, sob orientação do Prof. Dr. Renan Frighetto, 2008.

FRIGHETTO, Renan. Cultura e Poder na Antiguidade Tardia Ocidental. Curitiba, Juruá Editora, 2002.

FRIGHETTO, Renan. “O Rei e a Lei na Hispania Visigoda: Os limites da Autoridade Régia segundo a Lex Visigothorum, II, I - 8I 
de Recesvinto (652-670)" In: GUIMARÃES, Marcella Lopes e FRIGHETTO, Renan. Instituições Poderes e Jurisdições - I Seminário Argentina-Brasil-Chile de História Antiga e Medieval. Curitiba: Editora Juruá, 2007.

GIARDINA, Andrea. O Homem Romano. Lisboa: Editora Presença, s/d.

GERVÁS, Manuel. Propaganda Política Y Opinión Pública: em los panegíricos latinos Del Bajo Império. Salamanca: Universida de Salamanca, 1991.

HIDALGO DE LA VEJA, Maria José. El intelectual, la Realeza y el Poder Político em el Império Romano. Salamanca: Ediciones de Salamanca, 1995.

MENDES, Norma Musco. "Sistema Político do Principado". In: MENDES, Norma M. e SILVA, Gilvan. (org.) Repensando o Império Romano. Rio de Janeiro: Mauad; Vitória: EDUFES, 2006.

. Sistema Político do Império Romano do Ocidente: Um modelo de Colapso. Rio de Janeiro: DP\&A, 2002.

MOMiglianO, Arnaldo. Raízes Clássicas da Historiografia Moderna. São Paulo: Edusc, 2004.

MOMiglianO, Arnaldo. Os Limites da Helenização. Rio de Janeiro: Jorge Zahar, 1991. 
NICOLET, Claude. "El ciudadano y El político". In: GIARDINA, Andrea. El hombre romano. Madrid: Alianza Editorial, s/d. PEREIRA, Maria Helena da Rocha. Estudos de História da Cultura Clássica. Lisboa: Fundação Calouste Gulbenkian, s/d.

PETIT, Paul. A Paz Romana. São Paulo: Edusp, 1989.

SUÁRES, Domingo Plácido. "Las formas Del poder personal: la monarquia, la realeza y la tirania”. Revista Gerión, 2007, pp. 127-166.

ROSTOVTZEEF, Mikhael. História de Roma. Rio de Janeiro: Zahar Editores, 1973.

STADLER, Thiago David. O poder das palavras na idealização de um princeps - Epistolário Cruzado entre Plínio, o Jovem e Trajano (98-113 D.C). Dissertação de Mestrado apresentada ao programa de Pós Graduação da Universidade Federal do Paraná. Curitiba, 2010.

VENTURINI, Renata Lopes Biazotto. “As palavras e as Idéias: o Poder na Antiguidade. Diálogos". DHI/PPH/UEM, v. 9, n 2, pp. 142-155, 2005.

\section{Fontes utilizadas}

AUGUSTUS. Res Gestae Divi Augusti. London: Loeb Classical Library, 1924. 
. Os feitos do Divino Augusto. Belo Horizonte. Editoria UFMG, 2007

SUETÔNIO; AUgusto. A Vida e os feitos do Divino Augusto. Belo Horizonte. Editora UFMG, 2007.

VIRGÍlIO. Eneida. Trad. de Tassilo Orpheu Spalding. São Paulo: Nova Cultural, 2003.

. Eneida. Trad. De Vitoctorino Barreto Feio e José Maria da Costa e Silva. São Paulo: Martins Fontes, 2004.

Eneida. Disponível em site:

http://www.thelatinlibrary.com/verg.html. 